\title{
5 Research Square

\section{Synoptic situations in Africa south of the equator linked to wet events in Namibia; a case study with the February 2008 flood episode}

Chibuike Chiedozie Ibebuchi ( $\nabla$ chibuike.ibebuchi@uni-wuerzburg.de )

Institute of Geography and Geology, University of Würzburg, Am Hubland, 97074 Würzburg, Germany

\section{Research Article}

Keywords: Namibia, circulation types, rainfall, advection, Africa south of the equator

Posted Date: March 30th, 2021

DOl: https://doi.org/10.21203/rs.3.rs-368816/v1

License: (c) (i) This work is licensed under a Creative Commons Attribution 4.0 International License.

Read Full License 


\section{Abstract}

Namibia is one of the water stressed regions in sub-Saharan Africa, with an erratic rainfall pattern. This study investigates synoptic situations that can be favorable for wet events in Namibia. Obliquely rotated principal component analysis applied to the T-mode matrix (variable is time series and observation is grid points) of sea level pressure data set from NCEP-NCAR was used to characterize the modes of large-scale atmospheric circulation variability in Africa south of the equator, in the form of circulation types (CTs). 18 CTs were classified and the linkage of the CTs to wet events in Namibia showed that during austral summer and early austral autumn when sea surface temperature (SST) is warm at the southwest Indian ocean and continental heating is active on the southern African landmasses, stronger (weaker) anticyclonic circulation at the South Indian Ocean high-pressure (South Atlantic Ocean high-pressure) can be associated with enhanced low-level moisture advection by southeast (southwest) winds to Namibia, resulting in wet events in most regions in Namibia. Also, enhanced moisture uptake in the Mozambique Channel might compensate for a relatively weaker moisture advection rate by the South Indian Ocean high-pressure, so that enhanced rainfall can still be expected in Namibia under this scenario. During the early February 2008 flood episode in parts of Namibia, enhanced moisture uptake in the Mozambique Channel coupled with strong southeast winds advecting abundant moisture to Namibia was found to have contributed to the flood.

\section{Introduction}

Namibia, located in the western subtropical regions of southern Africa, has the least rainfall in subSaharan Africa (Dunaiski and Denning, 2019). Namibia lies between the Namib Desert to the west and the Kalahari Desert to the east. The climate in Namibia ranges from arid, semi-arid, and subtropical. With an estimated population of about 2.5 million inhabitants as of 2015 (WHO, 2018) and an annual average rainfall total of about $250 \mathrm{~mm}$, the region is water stressed to the extent that the country relies heavily on groundwater systems for agricultural and socio-economic sustenance (Shikangalah, 2020). Lu et al. (2016) found an increase in rainfall variability for the driest regions in Namibia for the 1998-2015 period. Anthropogenic climate change is expected to alter the regional rainfall patterns of Namibia and increase the variability of rainfall in the arid regions (IPCC, 2001). The vulnerability of Namibia to water stress is likely to increase also due to land-use changes (Thomas et al., 2005; Paeth et al., 2009) coupled with increasing population. According to (WFP, 2008), from January to April 2008, heavy and long-lasting rainfall lead to serious flooding in (northern) Namibia, significantly impacting food security in the region. These vulnerabilities make it necessary for improved rainfall forecasting skills for the local weather agencies in Namibia - as addressed in this paper from the standpoint of synoptic climatology.

The Benguela current and the South Atlantic Ocean high-pressure play significant roles in the aridity of Namibia through their influence on sea surface temperature (SST) anomalies at the east coast of the subtropical South Atlantic Ocean (Viguad et al., 2009). On the other hand, warm SST at the southwest and the tropical western Indian Ocean can be related to enhanced rainfall in southern Africa (Cook, 2000; 
Atlantic anticyclone can be associated with coastal SST variability in the southeastern Atlantic Ocean, due to the modifications of local alongshore winds. When atmospheric conditions are favorable, during warm events at the Benguela region, known as Benguela Niño, above-average rainfall can be expected in Namibia (Rouault et al., 2003; Reason and Smart, 2005). During El Niño years, modifications in atmospheric circulations in southern Africa, especially through the northeastward shift of the South Indian Ocean Convergence Zone can be associated with rainfall decrease in southern Africa (Cook, 2000). Previous studies have examined the variability of Namibia rainfall (e.g. Eckardt et al., 2013); this study uses a statistical approach of circulation typing in line with dynamical considerations to examine specific synoptic situations in Africa south of the equator that can be associated with wet events in Namibia. Also the synoptic condition during the February 2008 flood episode in Namibia, characterized as one of the worst floods in 50 years (Namibia Red Cross, 2008), is examined in the light of the circulation types designated by this study to be associated with wet events in the region.

\section{Data And Methodology}

Sea level pressure (SLP); specific humidity and wind vector at $850 \mathrm{hPa}$ data sets are obtained from NCEPNCAR reanalysis (Kalnay et al., 1996). The horizontal resolution of the data sets is $2.5^{\circ}$ longitude and latitude and the temporal resolution is daily from 1982-2019. Precipitation data sets are obtained from the Climate Prediction Centre (CPC) (Xie et al., 2007; Chen et al., 2008) and the Global Precipitation Climatology Centre (GPCC) (Ziese et al., 2020) at the horizontal resolutions of $0.5^{\circ}$ longitude and latitude and $1.0^{\circ}$ longitude and latitude, respectively. The temporal resolution of the precipitation data sets is daily from 1982-2019. Daily rainfall estimates from the GPCC precipitation data set is used to validate the CPC precipitation data set in Namibia for the 1982-2019 period. Thus both data sets are interpolated to a common $0.25^{\circ}$ longitude and latitude using First Order Conservative remapping.

To characterize the different modes of atmospheric circulation variability in Africa south of the equator, the concept of circulation typing is used. The spatial extent for the circulation typing is $0^{\circ}-50.25^{\circ} \mathrm{S}$ and $4^{\circ} \mathrm{E}-55.25^{\circ} \mathrm{E}$. It includes the adjacent oceans surrounding southern African landmasses which act as moisture sources.

Obliquely rotated principal component analysis (PCA) (Richman, 1981) is used in classifying the circulation types (CTs) in the target region. It is applied to the T-mode matrix of daily z-score standardized SLP data set for the 1982-2019 period. The variables are related using the correlation matrix, and singular value decomposition is used in factorizing the matrix to obtain the PC scores and the eigenvectors. The eigenvectors are multiplied by the square root of their corresponding eigenvalues which make them longer than a unit length, henceforth referred to as loadings (Richman and Lamb, 1985). The loadings localize in time the input (spatial) patterns captured by the PC scores (Compagnucci and Richman, 2008). The number of retained components is based on the recommendation of North et al. (1982) on the need for the separation of the eigenvalues; this is followed by a sensitivity analysis. The sensitivity analysis implies that after components with typically low and close eigenvalues are truncated, 
(Richman, 1981). The oblique rotation made at a power of 2 with Promax eliminates orthogonality constraint and maximizes the number of near-zero loadings so that each retained component clusters unique days with a similar input pattern (Richman, 1986). To enhance the coherency between the weather patterns clustered under each class, a subjective threshold of \pm 0.2 (Richman and Gong, 1999) is used to further cluster the loading in each retained component to negative high loadings and positive high loadings, above 0.2 , so that each retained component forms two classes. The mean SLP for the days clustered under each class is the CT.

The probability of each CT to bring wet days (daily rainfall amount averaged over Namibia $>1 \mathrm{~mm}$ ) in Namibia is calculated using Eq. 1.

$$
P_{W_{i}}=\frac{w_{i}}{N_{i}} \times 100 i=1 \ldots n
$$

$P_{w i}$ is the percentage of wet days in a given $C T, N_{i}$ is the total number of days clustered under a given CT, $\mathrm{W}_{\mathrm{i}}$ is the total number of wet days for the $\mathrm{CT}$ in question and $\mathrm{n}$ is the number of CTs classified. Also, the probability of the CTs to be associated with heavy wet days (daily rainfall amount averaged over Namibia $>10 \mathrm{~mm}$ ) is equally examined.

Since CTs are neither discrete nor confined to occur in specific season(s), the complete daily SLP data set is used for the classification. Focusing the classification on the wet seasons might eliminate useful information on the overall seasonal distribution of the CTs. However, the seasonality of CTs that are selected to be associated with wet events in Namibia is further analyzed to uncover if the CTs tend to be dominant at a specific season(s). The dominant period of a given CT is equally when its rain-bearing signal is most likely to be well expressed due to its persistence for a longer time.

Moisture flux is calculated as the product of specific humidity and wind speed. Composites of moisture flux at $850 \mathrm{hPa}$ and SLP are further used to analyze the patterns of moisture transport associated with the selected wet CTs.

\section{Results}

Figure 1 shows the seasonal rainfall climatology and Fig. 2 shows the time series for annual rainfall (top panel), and monthly cycle (bottom panel) of rainfall averaged over Namibia. It can be seen that both data sets agree that during austral summer (DJF), rainfall amount of up to $450 \mathrm{~mm} / \mathrm{season}$ can be expected in the north-eastern regions of Namibia. Austral winter (JJA) is the driest season. For the transition seasons, austral spring ( $\mathrm{SON}$ ) is relatively drier than austral autumn. The (western) regions at the east coast of the South Atlantic Ocean are relatively the driest throughout the year. The annual variations and magnitude of mean rainfall (Fig. 2, top panel) for the 1982-2019 period, from both data sets are quite by January (Fig. 2, bottom panel). 
9 components were retained for the circulation typing and each component yields two CTs - clusters of positive high loadings and negative high loadings - resulting in a total of 18 optimal CTs. Figure 3A shows the SLP composite (CTs) for each of the classes and Fig. 3B shows the rainfall composite for each of the CTs. Each CT is representative of a mode of variability in atmospheric circulation in the target region. Using the CPC precipitation data set and Eq. 1, the probability of a CT to be associated with wet days and heavy wet days in Namibia is obtained and the result is shown in Fig. 4. It can be seen that CT12 and CT18 (marked by the blue frames in Figs. 3A and 3B) have the highest probability to be associated with wet events in Namibia. On the other hand, CT6 and CT14 are dry CTs. They are mostly austral winter dominant CTs (not shown). The general attribute of the dry CTs is an anti-cyclonic circulation at the southwest Indian Ocean and strengthening of the South Atlantic Ocean anticyclone.

Figure 5 shows the annual cycle of the two CTs that relatively have a higher probability to be associated with wet events in Namibia. CT12 dominates mostly from November to February. CT18 dominates from February to April. Generally, these periods are characterized by a relatively more southward positioning of the Inter-Tropical Convergence Zone, warm SST at the south Indian Ocean, and southward shift of the semi-permanent high-pressure systems. For the two CTs, a cyclonic circulation is evident from the tropical Indian Ocean, towards the southwest Indian Ocean where an anti-cyclonic circulation dominates. Also, a low-pressure system is prevalent on most of the landmasses - an indication of continental heating.

Figure 6 shows the SLP, and moisture flux composites at $850 \mathrm{hPa}$, for the CTs selected to be associated with events in Namibia. First, for CT12, two rain-bearing synoptic situations are remarkable which makes it bring wet conditions to Namibia. First is a strong anticyclonic circulation at the South Indian Ocean high-pressure and second is the off-shore movement of thermal low into the South Atlantic east coast. As shown in Fig. 6, a stronger anticyclonic circulation at the South Indian Ocean high-pressure and the associating enhanced southeast winds drive moisture from the southwest Indian Ocean, far west to Namibia. The weakening of the South Atlantic Ocean high-pressure under this synoptic state might be related to the off-shore movement of the thermal low into the South Atlantic east coast and a direct implication is local alongshore wind modulation and warm SST. This equally implies that the influence of the South Atlantic Ocean anticyclone and the cold Benguela current on causing aridity in Namibia will be weakened. As a result, Fig. 3B shows that enhanced rainfall can be expected in large parts of Namibia, under the synoptic state of CT12.

Under CT18, the anticyclonic circulation at the South Indian Ocean high pressure is relatively weaker as compared to CT12, and this might be related to the strong cyclonic circulation (warm SST) in the Mozambique Channel, blocked by the South Indian Ocean anticyclone. The cyclonic system in the Mozambique Channel adjusts easterly winds to be westerly so that less moisture penetrates Namibia compared to CT12. Also, the relatively stronger South Atlantic Ocean anticyclone in this synoptic state can be seen in Fig. 5 to be equally associated with moisture driven away from the mainland. Even though moisture transport to Namibia is relatively weaker under CT18, precipitable water was found to be relatively highest in the Mozambique Channel under this synoptic state (Ibebuchi, 2021), and this might 
moisture to Namibia so that enhanced rainfall can still be expected in Namibia under this synoptic condition (Fig. 3B).

Finally, during the February 2008 flood episode in Namibia, Figs. 6 and 7 characterize the synoptic situations in Africa south of the equator, to foster analysis of the possible roles the synoptic conditions of CT12 and CT18 played during the flood event. According to the classification scheme, CT12 occurred 15 times from January to February 2008 and similarly, CT18 occurred 12 times. However, it is the persistence of the CTs that will determine to how extent their rain-bearing features will be expressed, given the continuum nature of atmospheric circulation. Table 1 and Table 2 show the periods that CT12 and CT18 persisted, respectively, for the January to February 2008 months. From the Tables, 9 to 11 February is remarkable - CT12 persisted for these days, and CT18 co-occurred with CT12 on 10 and 11 February. Figure 7 shows the composite of moisture flux at $850 \mathrm{hPa}$ and SLP for the aforementioned days, and it can be deduced that the synoptic features of both wet CTs are evident. First, for CT12 (i) a strong anticyclonic circulation at the western branch of the South Indian Ocean high-pressure, (ii) weaker state of the South Atlantic Ocean high-pressure, (ii) and enhanced moisture transport by easterlies into Namibia can be seen. For CT18, from the Mozambique Channel to the western tropical Indian Ocean, easterlies are translated to westerlies by the strong cyclonic system in the region - which is also an indication of enhanced convective activity in the Channel. Thus more moisture is equally available to be advected by the southeast winds into Namibia. For these days (i.e. 9 to 11 February 2008), based on the CPC data set, the average rainfall in Namibia is about $8 \mathrm{~mm} /$ day. From Fig. 8 , both the January and February composites of moisture flux indicate enhanced moisture advection into Namibia, by southeast winds. However, in the February composite, an enhanced cyclonic system (enhanced moisture uptake) is evident in the Mozambique Channel, so that despite a weaker advection rate - since easterlies are partly translated to westerlies - more moisture is available to be transported into Namibia during this month.

Table 1

Persistent periods of CT12 from January to

February 2008

\begin{tabular}{|ll|}
\hline Dates & Number of days \\
\hline $2008-01-11$ to $2008-01-12$ & 2 days \\
\hline $2008-01-14$ to $2009-01-15$ & 2 days \\
\hline $2008-02-9$ to $2008-02-11$ & 3 days \\
\hline $2008-02-21$ to $2008-02-22$ & 2 days \\
\hline
\end{tabular}


Table 2

Persistent periods of CT18 from January to

February 2008

\begin{tabular}{|ll|}
\hline Dates & Number of days \\
\hline $2008-01-30$ to $2008-01-31$ & 2 days \\
\hline $2008-02-10$ to $2008-02-11$ & 2 days \\
\hline $2008-02-26$ to $2008-02-27$ & 2 days \\
\hline
\end{tabular}

\section{Discussions}

This study examines synoptic situations in Africa south of the equator that can be associated with wet events in Namibia. Circulation typing was used to characterize the different modes of atmospheric circulation variability in the target region. Using obliquely rotated PCA on the T-mode matrix of SLP field for the 1982-2019 period, 18 CTs were classified. Each CT is physically meaningful and can be associated with the probability of a specific weather event in Namibia, in line with its underlying dynamics. Two synoptic situations were found to be associated with a high probability of wet events in Namibia. The synoptic situation that has the highest probability to be associated with wet events in Namibia is characterized by (i) cyclonic circulation from the tropical Indian Ocean towards the Mozambique Channel - an indication of moist convection over the oceans (Harr and Elsberry, 1995), (ii) stronger anticyclonic circulation at the South Indian Ocean high-pressure resulting to enhanced low-level moisture transport by southeast winds to Namibia, (iii) weaker South Atlantic Ocean anticyclone, and the off-shore movement of thermal low into the South Atlantic east coast - an implication of warm SST in the Benguela region. These synoptic situations are in agreement with existing works of literature (that were based on dynamical simulations) on the states of atmospheric circulation that can favor widespread rainfall in southern Africa. For example, Cook (2000), Lazenby et al. (2016), Washington and Preston (2006) reported that anomalous anticyclonic circulation at the South Indian Ocean high-pressure during austral summer correlates with above-average rainfall in southern Africa; here it is shown that when conditions are favorable, fluxes of moisture driven by the South Indian Ocean high-pressure might penetrate further west into Namibia. Reason and Smart (2015) reported that when SST is warm in the Benguela region, enhanced convergence of easterly and westerly winds can be associated with positive rainfall anomaly in Namibia. According to Richter et al. (2010) and Viguad et al. (2009), the weak state of the South Atlantic Ocean high-pressure can also be related to warm SST in the Benguela region.

The second synoptic state features enhanced cyclonic activity in the Mozambique Channel, coupled with relatively weaker southeast winds. The weaker anticyclonic circulation in the South Indian Ocean highpressure in this synoptic state might be related to warm SST in the Mozambique Channel (Morioka, 2015). This synoptic state suggests that when SST is anomalously warm in the Mozambique Channel, the rate of moisture transport into Namibia might be relatively weakened but this might be compensated by enhanced moisture uptake. 


\section{Conclusions}

At the synoptic scale, during austral summer and early austral autumn, when SST is warm in the southwest Indian Ocean, the offshore movement of thermal low into the South Atlantic Ocean coupled with stronger (weaker) anticyclonic circulation at the South Indian Ocean high-pressure (South Atlantic Ocean high-pressure) correlates with widespread rainfall in Namibia. Also, when moisture uptake is enhanced in the Mozambique Channel, low-level moisture transport by southeast winds, along $10^{\circ} \mathrm{S}-20^{\circ} \mathrm{S}$ into Namibia also correlates with wet events in the region. Generally, during wet seasons, enhanced convective activity in the southwest Indian Ocean and the Benguela region; strength and position of the semi-permanent high-pressure systems play vital roles in the circulation pattern controls of rainfall variability in Namibia.

Finally, during the February 2008 flood episode in Namibia, it was found that the synoptic conditions described in this paper to be associated with wet events in Namibia contributed to the heavy rainfall, based on their occurrence, and persistence for a longer period in early February.

\section{Declarations}

\section{Acknowledgments}

Thanks to NOAA/OAR/ESRL PSL and the Global Precipitation Climatology Centre for providing the NCEP/NCAR reanalysis, CPC, and GPCC precipitation data sets, respectively.

Conflict of interest: There are no conflicts of interest in this paper

Funding statement: This research received no specific grant from any funding agency in the public, commercial, or not-for-profit sectors

\section{References}

Chen, M., Xie, P., et al. (2008). CPC Unified Gauge-based Analysis of Global Daily Precipitation, Western Pacific Geophysics Meeting, Cairns, Australia, 29 July - 1 August, 2008.

Compagnucci, R. H., and Richman, M. B. (2008). Can principal component analysis provide atmospheric circulation or teleconnection patterns? Int J Climatol, 28 (6), pp. 703-726.

Cook, K. H. (2000). The South Indian Convergence Zone and Interannual Rainfall Variability over Southern Africa. J Clim, 13(21), pp. 3789-3804.

Dunaiski, C. M., and Denning, D. W. (2019). Estimated Burden of Fungal Infections in Namibia. Journal of Fungi, 5(3), pp. 75. 
Eckardt, F. D., Soderberg, K., Coop, L. J., Muller, A. A., Vickery, K. J., Grandin, R. D., Jack, C., Kapalanga, T. C., and Henschel, J. (2013). The nature of moisture at Gobabeb, in the central Namib Desert. J Arid Environ, 93, pp. 7-19.

Harr, A. P., and Elsberry, R. L. (1995). Large-scale circulation variability over the Tropical Western North Pacific. Part 1: spatial patterns and tropical cyclone characteristics. Mon Weather Rev, 123(5), pp. 12251246.

Ibebuchi, C. (2021). Can synoptic patterns influence the track and formation of tropical cyclones in the Mozambique Channel? Research Square, Preprint, viewed 19 February 2021, DOI: 10.21203/rs.3.rs200536/v1.

IPCC (2001) Climate Change 2001: Impacts, Adaptation, and Vulnerability. Contribution of Working Group II to the Third Assessment Report of the Intergovernmental Panel on Climate Change. Cambridge University Press, United Kingdom and New York, NY, USA.

Kalnay, E., et al. (1996). The NCEP/NCAR 40-year reanalysis project. Bull Amer Meteor Soc, 77(3), pp. 437472.

Lazenby, M. J., Todd, M. C., and Wang, Y. (2016). Climate model simulation of the South Indian Ocean Convergence Zone: mean state and variability. Clim Res, 68(1), pp. 59-71

Lu, X., Wang, L., Pan, M., Kaseke, F., and Li, B. (2016). A multi-scale analysis of Namibian rainfall over the recent decade - comparing TMPA satellite estimates and ground observations. J Hydrol Reg Stud, 8, pp. 59-68.

Morioka, Y., Takaya, K., Behera, S. K., and Masumoto, Y. (2015). Local SST Impacts on the Summertime Mascarene High Variability. J Clim, 28(2), pp. 678-694.

Namibia Red Cross (2008). Annual Report. Namibia. Available at: https://reliefweb.int/sites/reliefweb.int/files/resources/2EECF3D53B677FB6C12576340036EE67Full_Report.

Paeth, H., Born, K., Girmes, R., Podzun, R., and Jacob, D. (2009). Regional Climate Change in Tropical and Northern Africa due to Greenhouse Forcing and Land Use Changes. J Clim, 22(1), pp. 114-132.

Reason, C. J. C., and Smart, S. (2015). Tropical Southeast Atlantic warm events and associated rainfall anomalies over Southern Africa. Front Environ Sci, 3, pp. 24.

Richter, I., Behera, S. K., Masumoto, Y., Taguchi, B., Komori, N., and Yamagata, T. (2010). On the triggering of Benguela Niños: Remote equatorial versus local influences. Geophys Res Lett, 37, L20604.

Richman, M. B. (1981). Obliquely rotated Principal Components: an improved meteorological map typing 
Richman, M. B., and Lamb, P. J. (1985). Climatic pattern analysis of three and seven-day summer rainfall in the Central United States: some methodological considerations and regionalization. J Climate Appl Meteor, 24(12), pp. 1325-1343.

Richman, M. B. (1986). Rotation of principal components. J Climatol, 6(3), pp. 293-335.

Richman, M. B., and Gong, X. (1999). Relationships between the definition of the hyperplane width to the fidelity of principal component loadings patterns. J Clim, 12(6), pp. 1557-1576.

Rouault, M., Florenchie, P., Fauchereau, N., and Reason C. J. C. (2003). South east tropical Atlantic warm events and southern African rainfall. Geophys Res Lett, 30, pp. 8009.

Shikangalah, R. N. (2020). The 2019 drought in Namibia: An overview. J Namibian Stud: History Politics Culture, 27, 37-58.

Thomas, C. D., Cameron, A., Green, R. E., et al. (2004). Extinction risk from climate change. Nature, 427(6970), pp. 145-148.

Vigaud, N., Richard, Y., Rouault. M., and Fauchereau, N. (2009). Moisture transport between the South Atlantic Ocean and Southern Africa: relationships with summer rainfall and associated dynamics. Clim Dyn, 32(1), pp. 113-123.

Washington, R., and Preston, A. (2006). Extreme wet years over southern Africa: Role of Indian Ocean sea surface temperatures. Geophys Res Lett, 111, D15104.

WFP (2008). An assessment of the impact of the flood and other natural disasters on food security of rural households in areas of Northern Namibia (PDF)

World Health Organization Namibia Tuberculosis Profile. [(accessed on 1 January 2021)]; Available online: https://extranet.who.int/sree/Reports? op=Replet\&name=/WHO_HQ_Reports/G2/PROD/EXT/TBCountryProfile\&ISO2=NA\&outtype=html.

Xie, P., Chen, M., Yang, S., Yatagai, A., Hayasaka, T., Fukushima, Y., and Liu, C. (2007). A gauge-based analysis of daily precipitation over East Asia. J Hydrometeor, 8(3), pp. 607-626.

Ziese, M., Rauthe-Schöch, A., Becker, A., Finger, P., Rustemeier, E., and Schneider, U. (2020). GPCC Full Data Daily Version 2020 at $1.0^{\circ}$ : Daily Land-Surface Precipitation from Rain-Gauges built on GTS-based and Historic Data. DOI: 10.5676/DWD_GPCC/FD_D_V2020_100.

\section{Figures}



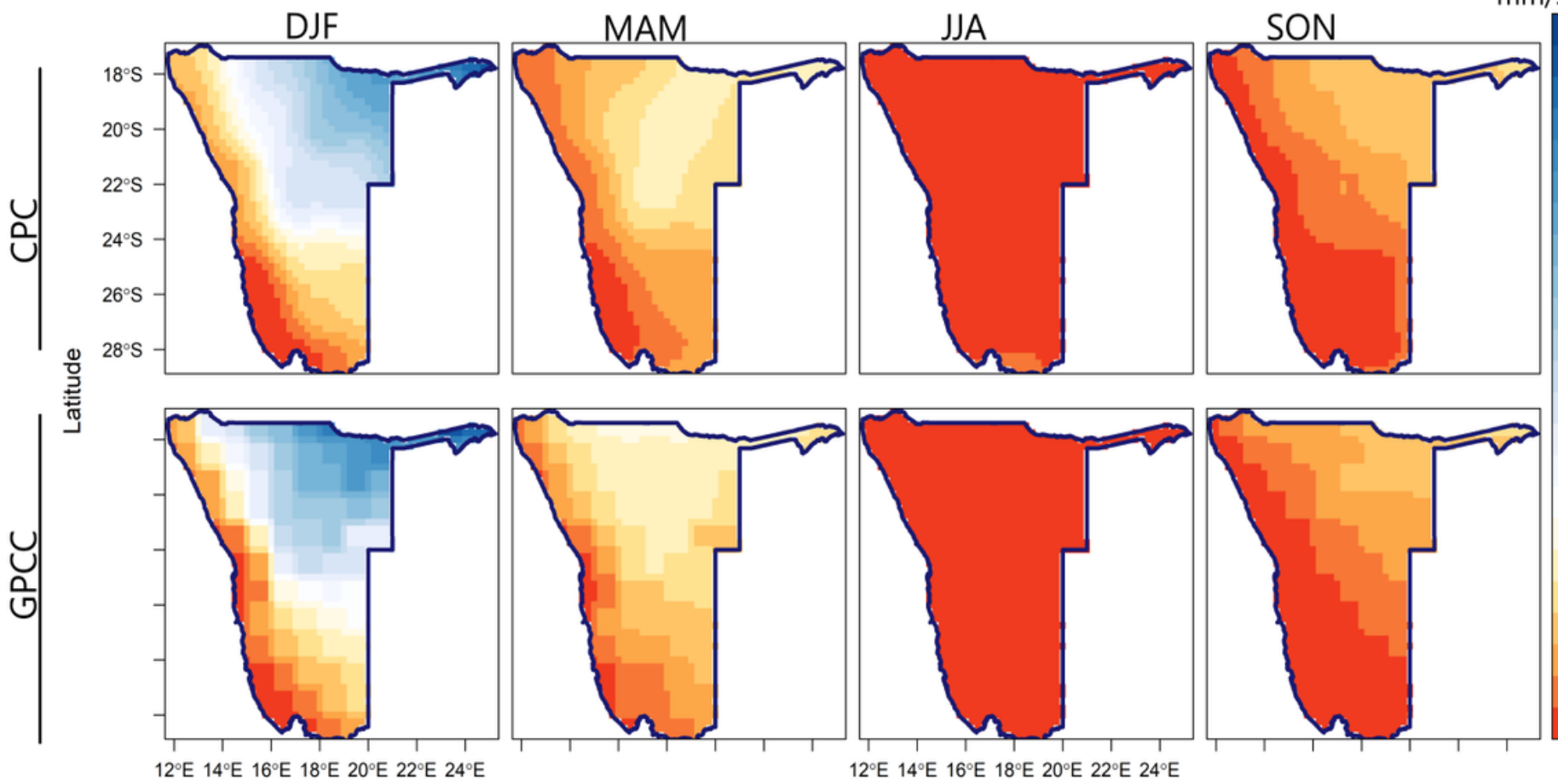

$\mathrm{mm} /$ season
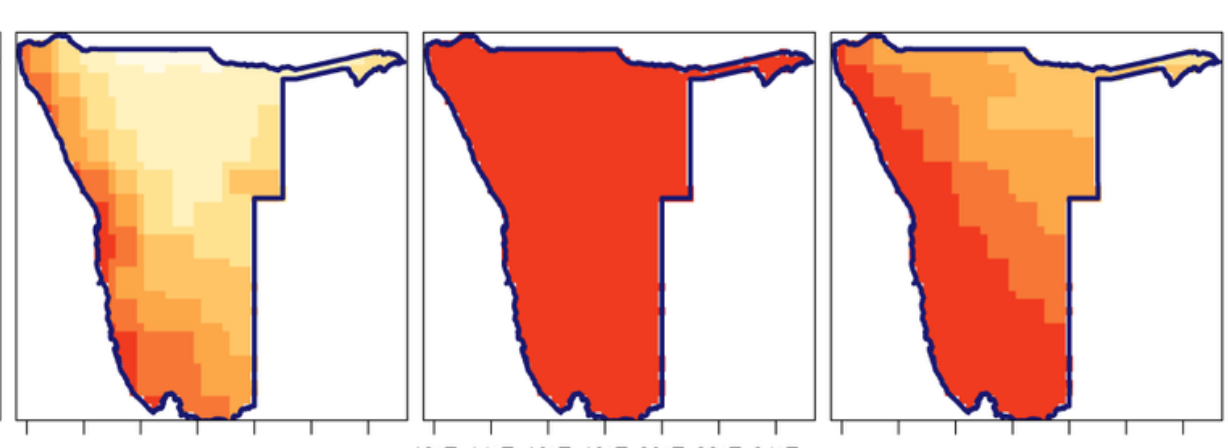

-440
-420

$-400$

$-380$

$-360$

340

$-320$

300

280

240

$-220$

$-200$

$-180$

160

140
120

$-100$

80

Longitude

Figure 1

Seasonal mean of precipitation in Namibia from the CPC and GPCC data sets for the 1982-2019 period. 

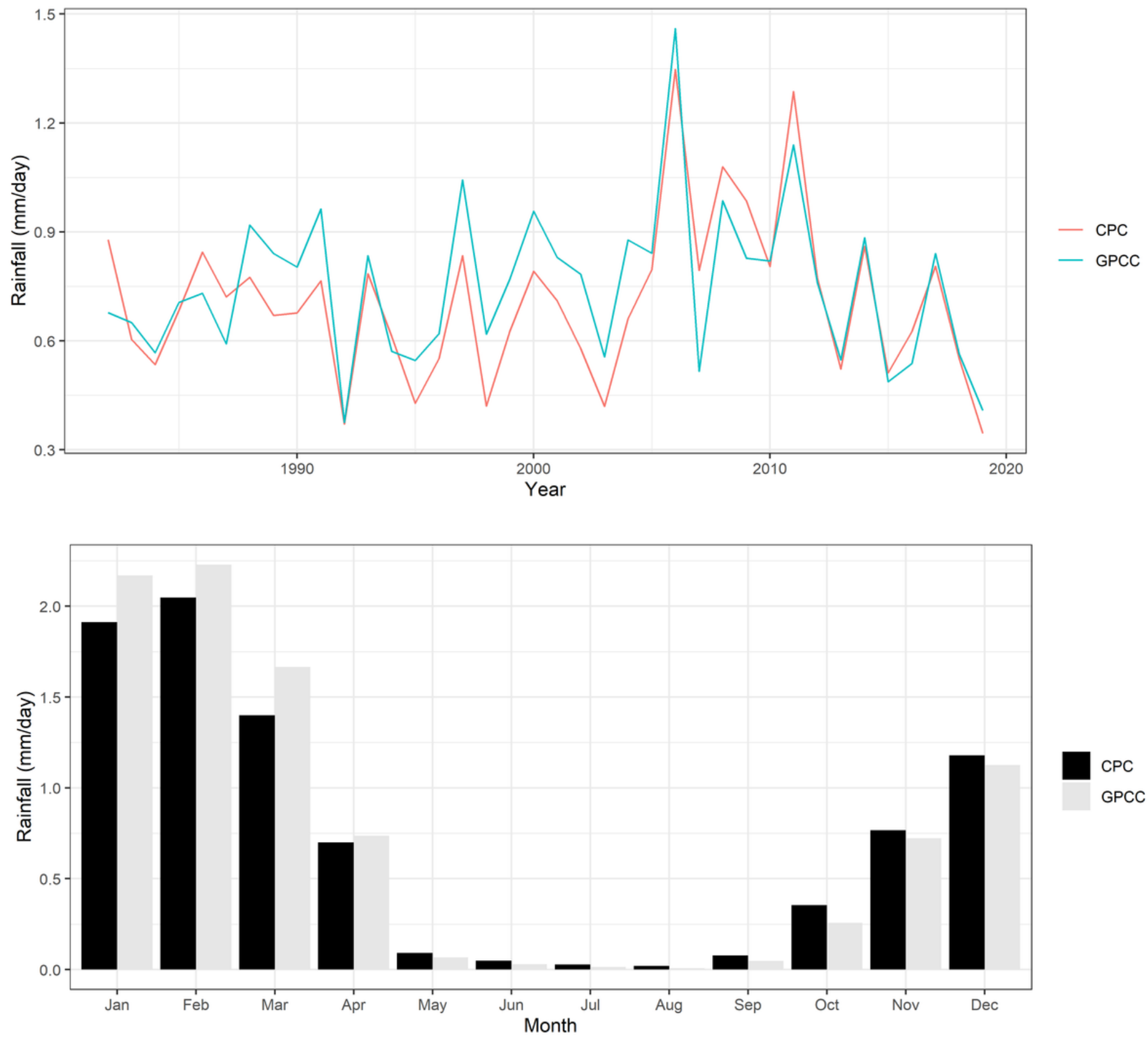

Figure 2

Time series of precipitation averaged over Namibia (top panel) and the monthly cycle of precipitation averaged over Namibia (bottom panel) for 1982-2019, from the CPC and GPCC data sets. 

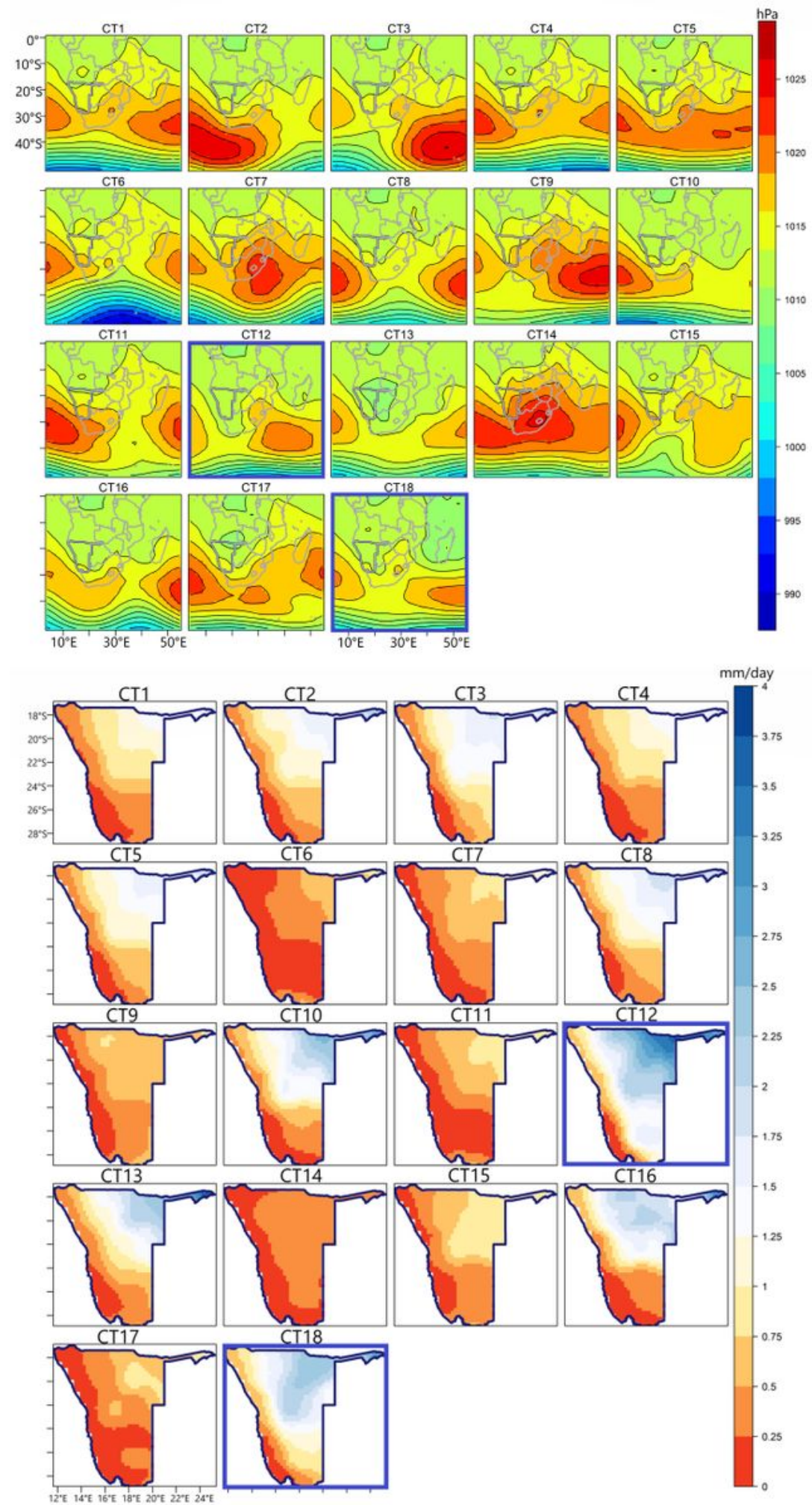

\section{Figure 3}

circulation types in Africa, south of the equator (A), and the associating rainfall composites in Namibia associated with the circulation types (B). The CTs are the mean SLP fields of the days clustered under a given class. The wet CTs are highlighted by the blue frames. 

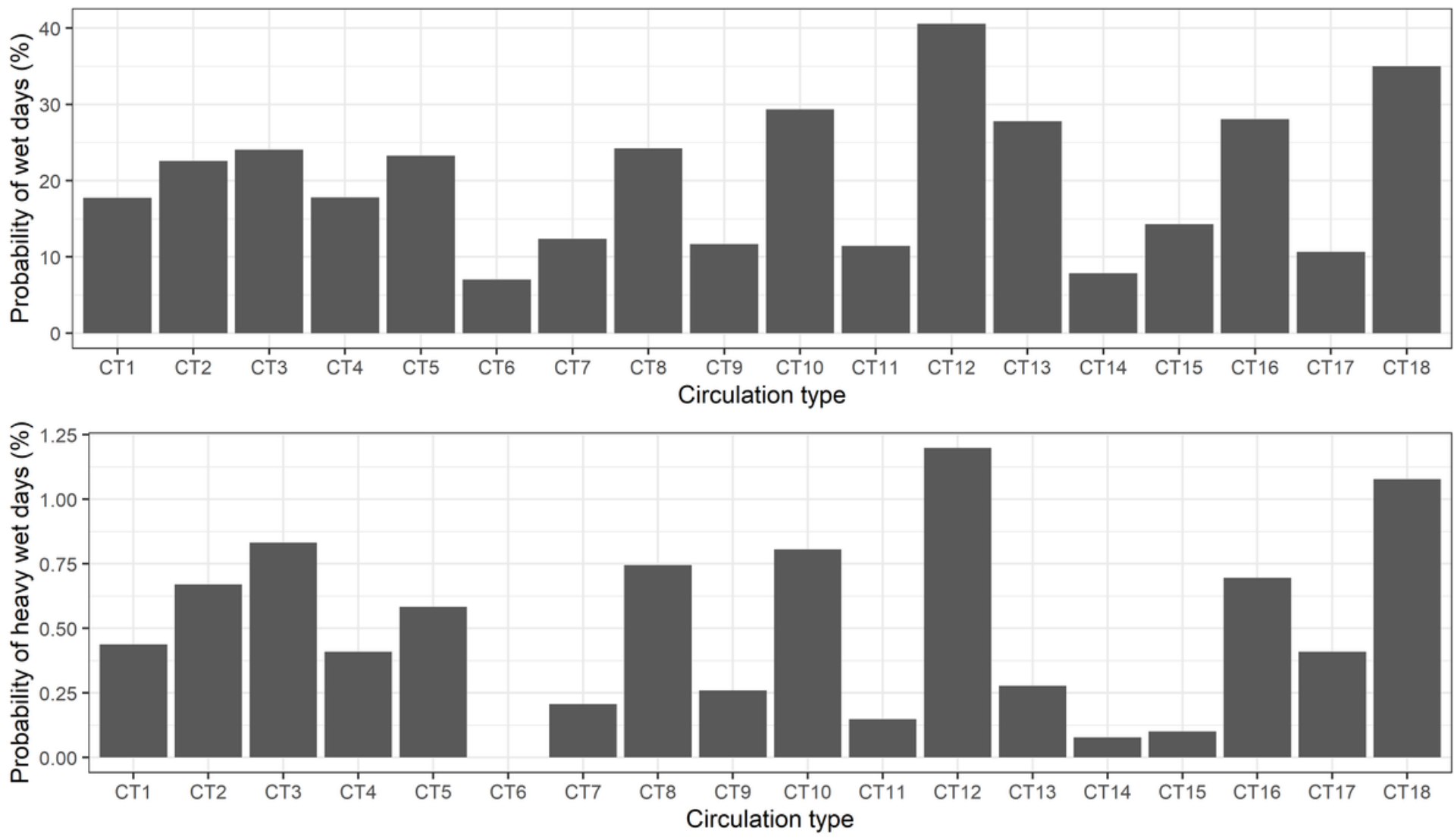

Figure 4

Probability of wet days (top panel) and heavy wet days (bottom panel) associated with the CTs in Figure 3. 


\section{CT12}

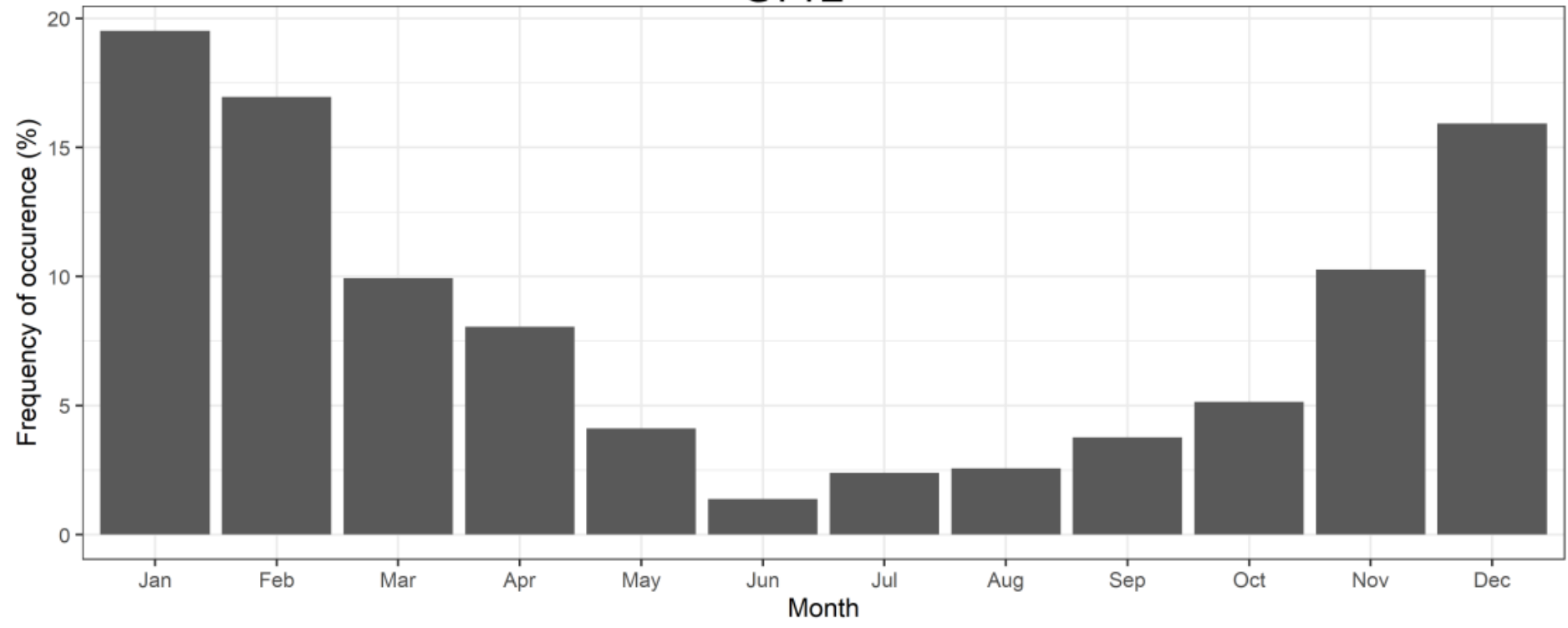

CT18

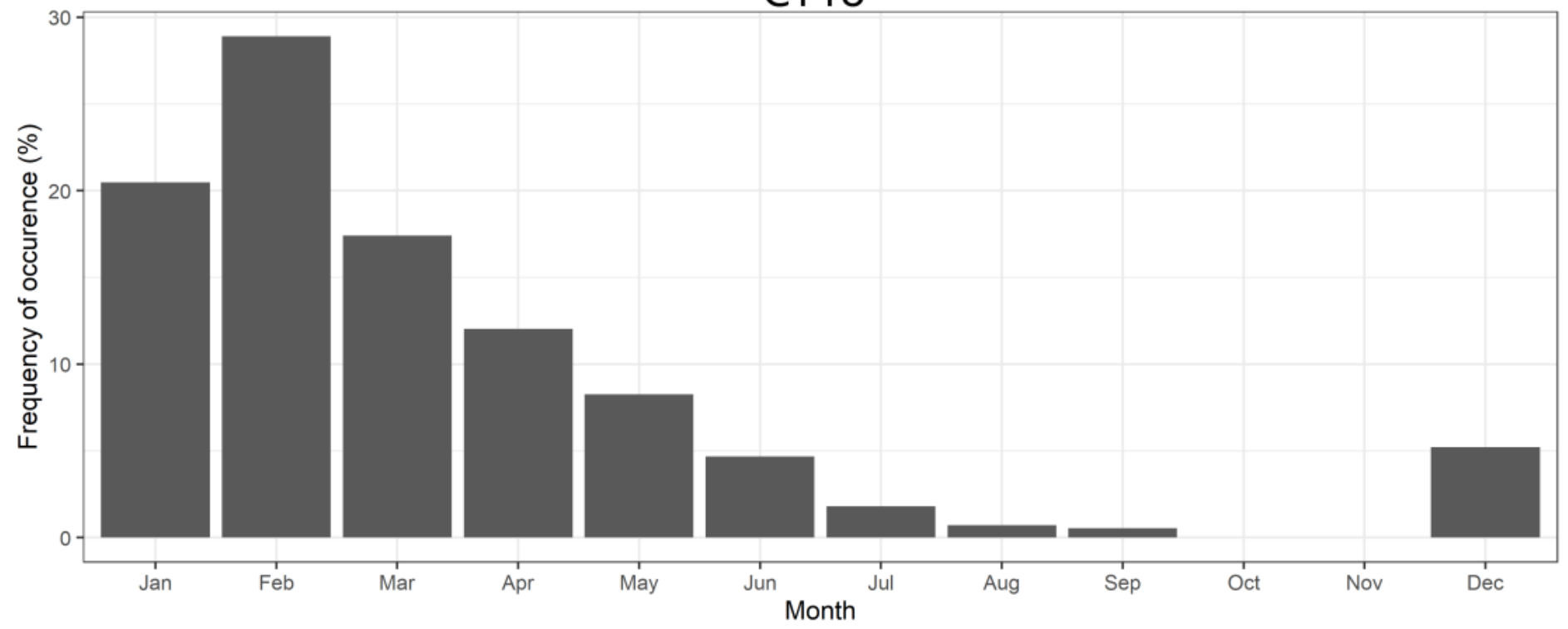

Figure 5

Annual cycle of the wet CTs. 

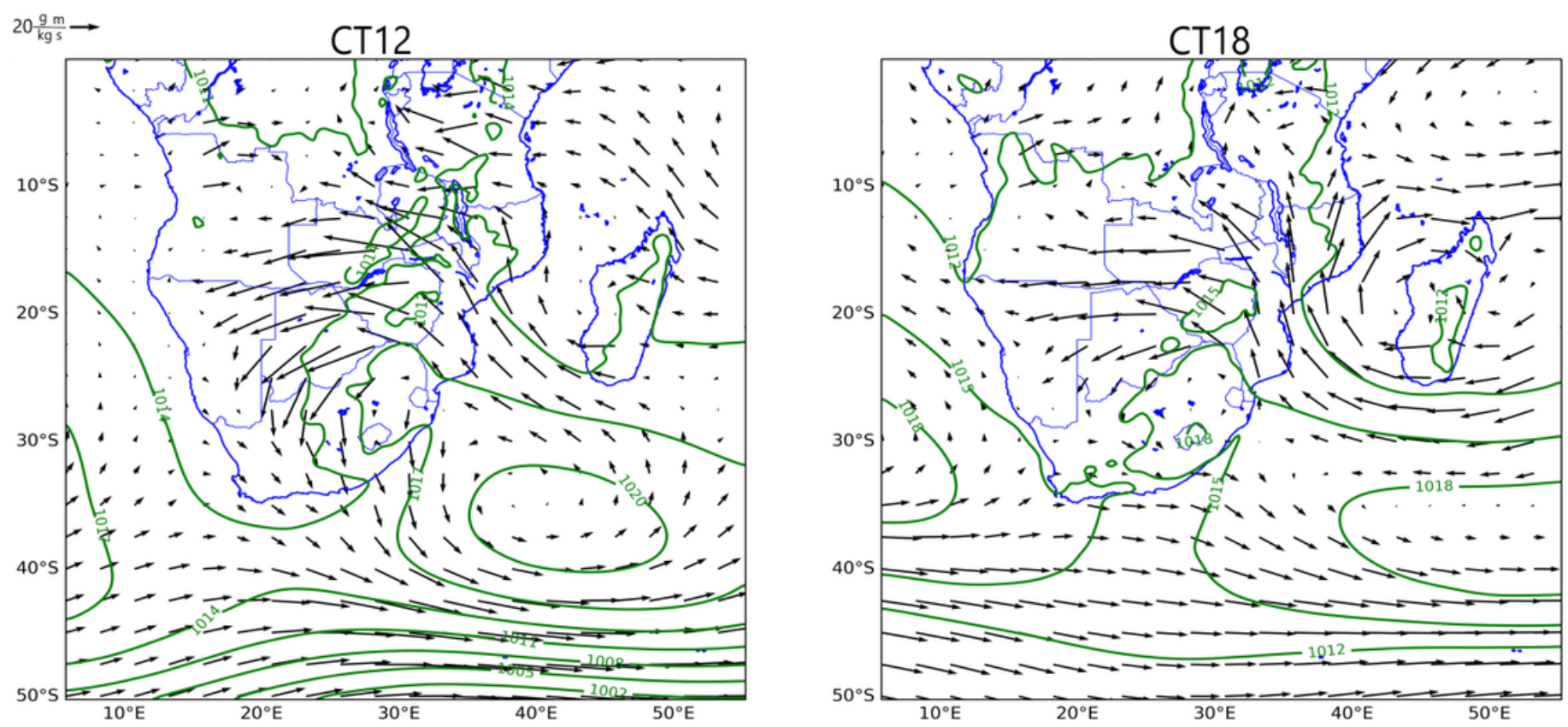

Figure 6

Composites of moisture flux (vectors) and SLP (contour lines) for the wet CTs. The Contour interval is 3 $\mathrm{hPa}$ and the scale of the vector is written on the map. 


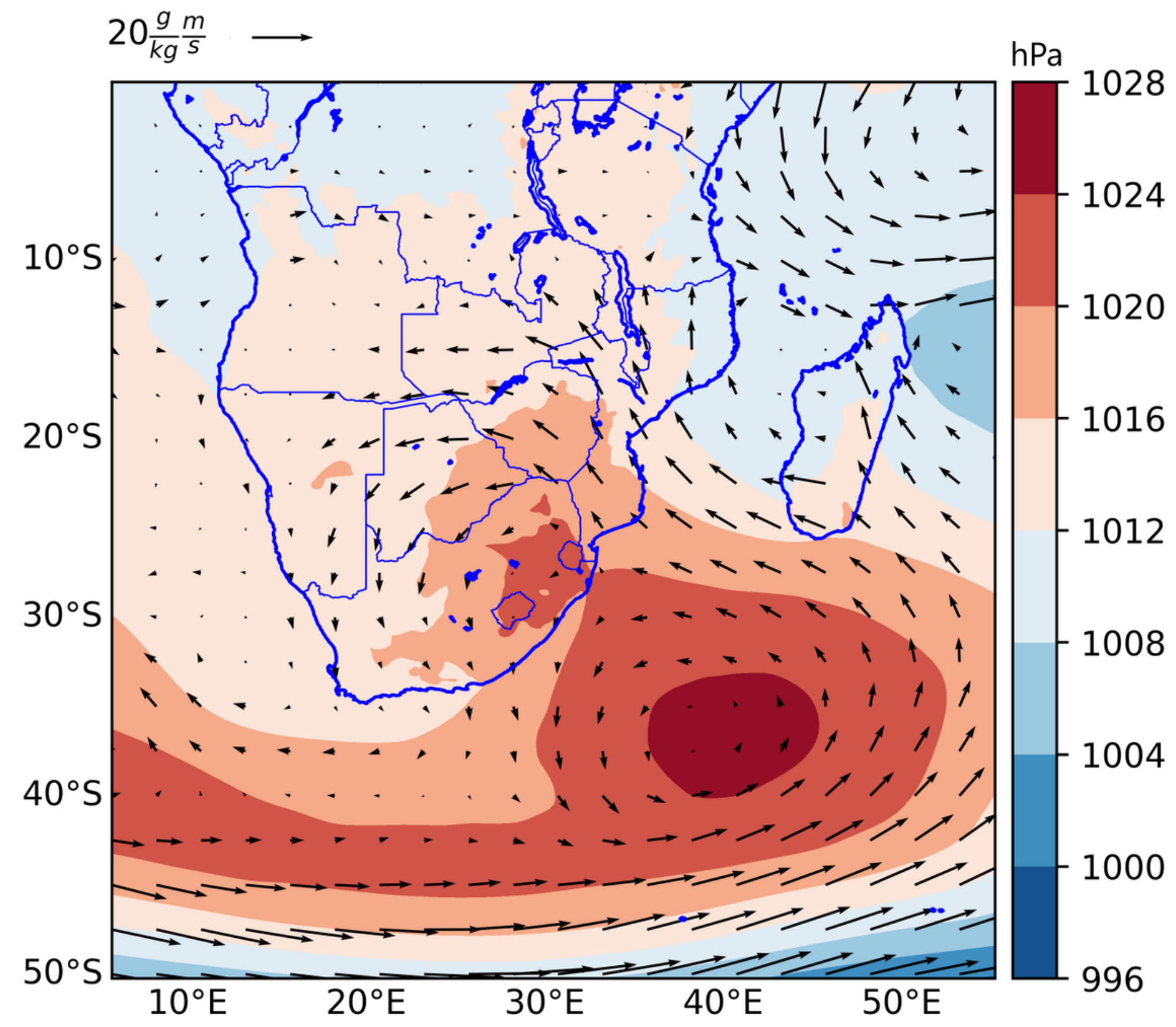

Figure 7

Composites of moisture flux at $850 \mathrm{hPa}$ and SLP, for 9 February to 11 February 2008, when CT12 persisted. Color is SLP and vector is moisture flux. The scale of the vector is written on the map. 

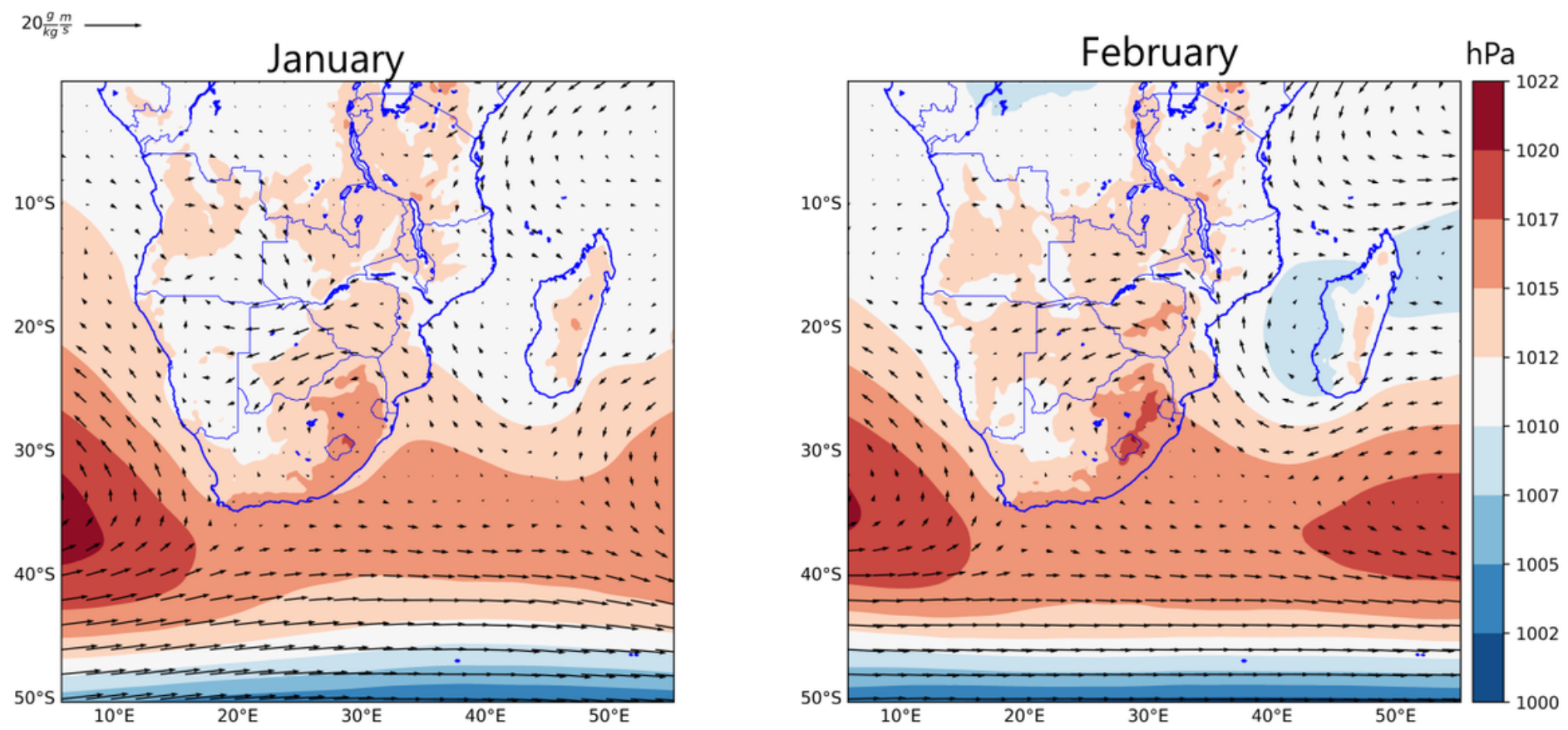

Figure 8

2008 January and February composites of SLP and moisture flux at $850 \mathrm{hPa}$ in Africa south of the equator. Color is SLP and vector is moisture flux. The scale of the vector is written on the map. 